\title{
Repellent Effects of Aloe pirottae (Aloaceae) Gel Extract and Brassica nigra (Brassicaceae) Essential Oil against the Malaria Vector, Anopheles arabiensis Patton (Diptera: Culicidae)
}

\section{Bekele $D^{1 *}$ and Petros $\mathrm{B}^{2}$}

${ }^{1}$ Department of Biology, College of Natural and Computational Sciences, University of Debre Markos, Ethiopia

${ }^{2}$ Department of Microbial, College of Natural Sciences, Cellular and Molecular Biology, University of Addis Ababa, Ethiopia

\begin{abstract}
Malaria continues to be one of the major public health challenges in the world, particularly in Africa, despite the fact that numerous studies have identified effective methods of control. The plant species that include Brassica nigra (seeds) and Aloe pirottae (leaves) in Ethiopia were used traditionally as mosquito repellent and selected for the mosquito repellent activity test. The present study was undertaken to scientifically evaluate the repellent activity of two extracts from Aloe pirottae and Brassica nigra, respectively on forearms of human volunteers against Anopheles arabiensis mosquito under laboratory conditions. Four concentrations: $2.5,5,10$ and $20 \%$ of the repellents were evaluated. The safety of these extracts was tested to make a further research and results showed no dermal irritation actions. In the course of our test for repellents against Anopheles arabiesnis, the oil extract of Brassica nigra was found to exhibit more remarkable repellent activity than gel extract of Aloe prottae with $\mathrm{ED}_{50}$ of $1.468 \%$ and $16.689 \%$, respectively after $6 \mathrm{~h}$ exposure. The Chi-square values were significant at $p<0.05$ level. The present study indicates that the extracts derived from Aloe pirottae and Brassica nigra have good efficacy in mosquito repellency, thus their extracts could be used in the regulation of malaria vector. These extracts had no adverse effects on rabbits at $20 \%$ concentration. Further studies are required to determine formulations with enhanced activity against mosquitoes and their cost effectiveness. The field bioassays also need to be evaluated as the present study indicated the scope to use local plants to augment the ongoing malaria vector control.
\end{abstract}

Keywords: Repellent plants, Aloe pirottae, Brassica nigra, Anopheles arabiensis, malaria, essential oil, gel extract, DEET

\section{Introduction}

Malaria is a global infectious disease caused by Plasmodium species transmitted by mosquitoes of the genus Anopheles. The World Health Organization [1] estimated about 3.2 billion people to be at risk of malaria globally. Out of these, $89 \%$ of the cases and $91 \%$ of the deaths occurred in sub-Saharan Africa while the remaining cases and deaths occurred mainly in South-East Asian and Eastern Mediterranean Regions. The high impact in Africa is partly because most malaria infections in sub-Saharan Africa are caused by the most severe and lifethreatening form of the disease, namely Plasmodium falciparum [2]. Malaria is understood to be both a cause of poverty and a disease of poverty [3], with $58 \%$ of malaria cases occurring in the poorest $20 \%$ of the world's population, where people receive inadequate health care and suffer severe economic consequences from the illness [4].

The control of malaria in Ethiopia until recently relied upon case treatment and vector control through application of insecticides to the interior surfaces of houses and use of treated bed nets. However, the efficacy of these strategies to control malaria parasite and malaria vector are compromised by the parasite resistance to antimalarial drugs and mosquito resistance to insecticides. Resistance to insecticides is a serious problem of malaria control efforts in all regions where insecticides are used to kill mosquitoes. Anopheles arabiensis are the most important malaria vector in Ethiopia, which is strongly resistant to DDT and pyrethroids [5-7].

Repellents prevent human-mosquito contact by acting as an irritant to the mosquitoes. They are applied directly to skin or clothing or other fabrics e.g. arm and ankle bands, or mosquito screens. The local communities adapt various methods to repel the insects and/or mosquitoes. Application of smoke by burning the plant parts is one of the most common practices among the local inhabitants. Other types of applications are spraying the extracts by crushing and grinding the repellent plant parts, hanging and sprinkling the repellent plant leaves on the floor. Another study by Waka, et al. [8] stated that local plants with repellent or insecticidal action may play an important role in regions where mosquitoes bite in the early evenings or in situations when there are not enough bed nets to cover all the beds in a house.

Many popular practices exist to avoid the nuisance of mosquito bites such as fumigation, burning green leaves on the hut's threshold, mosquito coils, insecticide sprays, and repellents. Smoke is a common method of repelling biting mosquitoes that is used throughout the world [9]. They are also important where drug resistant parasites and insecticide resistant vectors prevail. This repellency of plant material has been exploited for thousands of years by man, most simply by hanging bruised plants in houses, a practice that is still in wide use throughout the developing countries [10]. Utilising home-grown repellents shall reduce the need for foreign imports where the exchange rate inequalities and transport costs inflate expenditure. As well as being cheap and locally available, natural repellents are normally culturally acceptable and locally known. Plants used as repellents are particularly beneficial

*Corresponding author: Bekele D, Department of Biology, College of Natural and Computational Sciences, University of Debre Markos, Ethiopia, Tel: 0912-179124 E-mail: damtish99@yahoo.com

Received: November 03, 2016; Accepted: September 21, 2017; Published September 29, 2017

Citation: Bekele D, Petros B (2017) Repellent Effects of Aloe pirottae (Aloaceae) Gel Extract and Brassica nigra (Brassicaceae) Essential Oil against the Malaria Vector, Anopheles arabiensis Patton (Diptera: Culicidae). Biochem Anal Biochem 6: 336. doi: 10.4172/2161-1009.1000336

Copyright: @ 2017 Bekele D, et al. This is an open-access article distributed under the terms of the Creative Commons Attribution License, which permits unrestricted use, distribution, and reproduction in any medium, provided the original author and source are credited. 
Citation: Bekele D, Petros B (2017) Repellent Effects of Aloe pirottae (Aloaceae) Gel Extract and Brassica nigra (Brassicaceae) Essential Oil against the Malaria Vector, Anopheles arabiensis Patton (Diptera: Culicidae). Biochem Anal Biochem 6: 336. doi: 10.4172/2161-1009.1000336

Page 2 of 7

for rural areas where access to commercial preparations is minimal and expense is a limiting factor.

Natural and synthetic insect repellents are well established as means of personal protection against biting arthropods and the various pathogens they may carry [11]. According to authors [12,13] although considerable efforts have focused on botanicals for potentially useful products as commercial insecticides, few plant products have reached the market and their efficacy is still lower than that of currently used synthetics.

The use of traditional repellents is widespread among the different cultures and communities of Africa and beyond [14]. For centuries, people used smoke from burning cattle or goat dung to drive out mosquitoes from their caves or huts before sleeping [15]. Some communities were used smoke with certain herbs and barks of some trees by adding to the smoldering fire to deter mosquitoes from entering the home [16]. Natural based oils and plant extracts have been considered as potential insecticides, particularly because the availability of such substances within a local setting greatly reduces cost of large scale manufacture. Some indigenous plant based products are very promising as mosquito repellents [17], offering an alternative to synthetic compounds that can be obtained by individuals and communities at very low cost [18].

Currently, the US Environmental Protection Agency (US EPA) has registered citronella, lemon and eucalyptus oils as insect repellent ingredients for application on the skin; these natural products are been frequently used due to their relative low toxicity, comparable efficacy, and customer approval [19]. In response to whether plant extract can cause contact dermatitis or not, It has been suggested that when using these products for insect repellency or control, the preparation should be rubbed on a small portion of skin of animal to determine if there will be an allergic reaction before treating your whole body [20].

Repellents applied to skin and clothing's are of great importance in protecting human beings from mosquito attack. Their mode of action and how repellents function vary with the specific nature of the repellent, which include barrier and volatile. Many potential natural repellents can be considered as a barrier to the insect, preventing either landing or penetration of the skin. In many cases, these barrier compounds can be skin lotions or sun screens [21]. With barrier repellents, an insect may land but not be able to bite. However, in the case of volatile products their efficacy relies on vapor pressure and temperature to release specific chemicals that insects avoid [22].

According to World Health Organization [23], more than $80 \%$ of the population in developing countries relies on traditional medicine, and it is now widely accepted that traditional medicines are more affordable, less toxic, and have a wide acceptance around the world. Like other developing countries, medicinal plants have been used as remedies for many years and are still remain the most important in Ethiopia. The plant extract from Aloe pirottae (A. pirottae) is reported for its current use to treat malaria and insect repellent in Babile District, eastern Ethiopia [24]. It is reported that plant species that include A. pirottae and $B$. nigra are traditionally used for insect repellents and insecticides in Akaki District [25] and also have mosquitocidal effects against $A$. arabienis [26]. The selection of $A$. pirottae and B. nigra were based on its use in traditional medical practices and as insecticide confirmed from ethnobotanical research made in Ethiopia. However, there was no information on mosquito repellent effects against Anopheles arabiensis (A. arabiensis).

Information on B. nigra and A. pirottae indigenous Ethiopian plants against mosquito vectors are dominated by oral tradition and is not scientifically well documented. This traditional information is further complicated by loss of biodiversity and tradition. In this context, our traditional knowledge on plant-based insect repellents would be immensely valuable and helpful. The literature, however, offers no data about the repellent activities of these selected plants against $A$. arabiensis. The first step in understanding the repellent properties of these plants requires research to test for efficacy and safety to validate traditional medicinal beliefs, and thus this investigation has been carried out to achieve this end. The purpose of this study was to investigate the possible mosquito repellent potential of the oil of B. nigra (L.) Koch (Brassicaceae) and the gel extract of $A$. pirottae Berger (Aloaceae) against $A$. arabiensis, the principal vector of malaria in Ethiopia.

\section{Materials and Methods}

\section{Selection and collection of the plant materials}

The information in the selection of plant species for the repellent test against $A$. arabiensis was based on ethnobotanical information, existing literature and interview to local community members during study visits. Leaves of $A$. pirottae Berger (Family: Aloaceae), Aloe (Eng) were collected from Iftu locality of Babile District (latitude: 09012.494'N, longitude: $042015.228^{\prime} \mathrm{E}$ ) and this plant species grows in between 1300 and 1820 metres above sea level (mASL) [27]; not known elsewhere (i.e. endemic to Ethiopia). Seeds of B. nigra L. Koch (Family: Brassicaceae), black mustard (Eng) were collected from Yerer Lencho locality of Akaki District (latitude: 08047.144'N, longitude: 038053.712'E) and grows in between 1600 and $2450 \mathrm{mASL}$ [28]. Both plant species were collected from Oromia Region, Ethiopia. These candidate plant species were collected both through initial literature search followed by field searching in a series of ethnobotanical survey in Akaki and Babile Districts. It was authenticated by a plant taxonomist in the Department of Plant Biology and Biodiversity Management, Addis Ababa University. Voucher specimens from field-collected samples were deposited at the National Herbarium found at College of Natural Sciences in Addis Ababa University.

\section{Rearing Anopheles arabiensis patton}

Eggs of A. arabiensis mosquitoes were obtained from the insectary of the Ethiopian Public Health Institute (EPHI) research center, Addis Ababa, Ethiopia. The colonies were reared and maintained in cages (30 $\mathrm{cm} \times 30 \mathrm{~cm} \times 30 \mathrm{~cm})$ under controlled temperature $\left(25-30^{\circ} \mathrm{C}\right)$, relative humidity $(70-80 \%)$ and light-dark $(12 \mathrm{hr}: 12 \mathrm{hr})$ photoperiod at the insectary of the College of Natural Sciences, Addis Ababa University according to standard World Health Organization (WHO) procedure [29]. Glass petridishes ( $10.5 \mathrm{~cm}$ internal diameter) lined with wet filter paper were kept inside the cages for oviposition, then eggs laid on the filter paper were transferred to plastic and enamel trays containing three liters distilled water and allowed to hatch to first instar larvae and kept until they reach the pupae. The larvae were fed on finely ground Tetramin fish food pellets (Tetra holding Inc., Blacksburg, VA, USA); the feed was applied on alternate days for normal development. Water of the larval culture was changed every third day to avoid decay. The trays containing the larvae were kept in the sun during the early morning hours for keeping the water aerated. After attaining pupae, they were transferred to beakers by disposable pipettes and kept inside the mosquito cages for adult emergence. Food for sustaining Anopheles arabiensis adults in cages $(30 \mathrm{~cm} \times 30 \mathrm{~cm} \times 30 \mathrm{~cm})$ was provided continuous access to $10 \%$ sucrose solution. The cotton-wool was moistened daily and changed twice weekly. Adult female A. arabiensis were periodically blood-fed on restrained rabbits shaved on the side 
Citation: Bekele D, Petros B (2017) Repellent Effects of Aloe pirottae (Aloaceae) Gel Extract and Brassica nigra (Brassicaceae) Essential Oil against the Malaria Vector, Anopheles arabiensis Patton (Diptera: Culicidae). Biochem Anal Biochem 6: 336. doi: 10.4172/2161-1009.1000336

Page 3 of 7

of their belly for fertile egg production and the feeding was stimulated by darkening the cage. The $A$. arabiensis reared in the laboratory thus served as the source of adults for the bioassay tests.

\section{Preparation of the extract}

The gel of A. pirottae ( $495 \mathrm{~g}$ ) was extracted three times by maceration with $3 \mathrm{~L}$ of $80 \%$ methanol (SCP, England) at room temperature for 72 h. The extract was filtered through a Buchner funnel with Whatman number 1 filter paper (Whatmann, England). The filtrate was concentrated using a rotary vacuum evaporator (Staurt $\left.{ }^{\circ} \mathrm{RE} 300, \mathrm{UK}\right)$, $22-26 \mathrm{~mm} \mathrm{Hg}$ below $45^{\circ} \mathrm{C}$. The extract thus obtained was concentrated further over water bath (Kottermann, Germany) by evaporating the solvent. The A. pirottae extracts were pink and stored at $-20^{\circ} \mathrm{C}$ until bioassay. Standard stock solutions were prepared at $1 \%$ by dissolving the residues in absolute ethanol in two drops of dimethyl sulphoxide (DMSO) universal solvent. From the stock solution desired concentrations were prepared. Essential oil from B. nigra was obtained by hydrodistillation using Clevenger apparatus. The seeds of $B$. nigra (735 g) was powdered and dissolved in $1200 \mathrm{ml}$ of distilled water and placed in an electric sand path. At the end of distillation for $5 \mathrm{~h}$ the sand path was shut off and the distillated oil was withdrawn from the apparatus tap in a small vial, dehydrated over anhydrous sodium sulphate and stored at $0^{\circ} \mathrm{C}$ until used in bioassay tests and GC analysis.

\section{Dermal irritation test}

Before undertaking tests on humans, preliminary safety studies of the tested plant products were carried out in rabbits as reported by Garud et al. [30]. Four healthy rabbits were purchased from the Laboratory Animal Center of EPHI were treated topically with $20 \%$ concentration of each of $A$. pirottae gel extract and $B$. nigra seed oil by direct application to shaved back skin of the left dorsal and trunk area $(3 \mathrm{~cm} \times 3 \mathrm{~cm})$. The same area of shaved skin on the right side of the animal was used as the control (no application). Skin reactions were scored after 3, 6 and $9 \mathrm{~h}$ of exposure period based on the degree of erythema and edema as described by the method of Driaze, et al. [31]. The Primary Skin Irritation Index (PSII) gave an idea of the skin irritancy nature of the prepared concentration [32]. The extract which elicited no irritant response or a minimal response in rabbits were considered as unlikely to cause irritation in man. The skin reaction values tested on rabbit was, therefore, with respect to safety for contact with intact human skin.

\section{Mosquito repellency test}

The human-topical application technique [33], which was conducted to determine the repellent efficacy of the gel extract of $A$. pirottae and essential oil of $B$. nigra against 100 female $A$. arabiensis that were between 5-7 days old post-emergence, blood-starved for $12 \mathrm{~h}$ but previously fed on $10 \%$ sucrose solutions socked in cotton wicks were placed into separate laboratory test cages $(30 \mathrm{~cm} \times 30 \mathrm{~cm} \times 30 \mathrm{~cm})$ and left to acclimatize for $1 \mathrm{~h}$. Various test solutions of the gel extract of $A$. pirottae and essential oil of $B$. nigra were prepared in absolute ethanol (HPLC grade) and DMSO. The highest concentration was $1 \%(0.1 \mathrm{mg} /$ $\mathrm{ml}$ ). Therefore, the bioassayed doses were of $2.5 \%, 5 \%, 10 \%$ and $20 \%$ and each concentration was tested after 3, 6, 9 and $12 \mathrm{~h}$ exposure. The screening was done sequentially starting with the lowest dose $(2.5 \%)$ and ending with the highest one (20\%). The arms of the volunteer skin were washed with unscented soap and cleaned with ethanol. Each of a test solution $(0.1 \mathrm{ml})$ of $A$. pirottae gel extract and $B$. nigra oil was dispensed separately on the right forearm of a volunteer from the wrist to the elbow. The adjacent forearm treated with a similar dose mixture of absolute ethanol $(0.1 \mathrm{ml})$ and 2 drops of DMSO was dispensed on the left forearm, to act as a negative control. The 20\% DEET (N,N-diethylmeta-toluamide; $95.0 \%$ purity) served as a positive control with the $A$. pirottae gel extract and B. nigra oil prepared at a concentration of $20 \%$ were used in the test. Only $25 \mathrm{~cm}^{2}$ dorsal side of the skin on the each arm was exposed and the remaining area was covered by rubber gloves. Both arms were introduced simultaneously into the cages, and the numbers of mosquitoes that landed and/or bites were counted and recorded in the treated and control arm in $5 \mathrm{~min}$, every $30 \mathrm{~min}$ from 18:00 $\mathrm{h}$ to $06: 00 \mathrm{~h}$ at $25-30^{\circ} \mathrm{C}$ and $70-80 \%$ relative humidity, and a $12: 12$ (light: dark) photoperiod. After the bioassay of each concentration, the arms were washed with bar soap, rinsed well with tap water and then allowed to dry for 15-20 min, before application of the next dose of the test sample. The dose response study was carried out until the concentration of test extract and/or oil giving complete protection of landing or biting mosquitoes. Protection time was recorded as the time elapsed between repellent application and the observation period immediately preceding the first confirmed bite. Identical tests were replicated three times using a fresh batch of mosquitoes on different days on each subject of six human volunteers. The plant-derived repellent was applied randomly to each participant, and no one tested more than one preparation per day.

\section{Analysis of B. nigra oil by gas chromatography}

Constitutional analysis of B. nigra oil was carried out on gas chromatography (Shimadzu GC-2010, Shimadzu, Japan) equipped with a flame ionization detector under the following conditions: injection of $0.1 \mu \mathrm{l}$ of $B$. nigra oil, with a split ratio of 400:1; an SGE BP-20 capillary column $0.25 \mathrm{~mm}$ i.d. $\times 50 \mathrm{~m}$ fused silica coated with DB-1, film thickness $0.25 \mu \mathrm{m}$; the oven temperature was programmed from 50 to $200^{\circ} \mathrm{C}$ at $2^{\circ} \mathrm{C} / \mathrm{min}$; injection temperature $220^{\circ} \mathrm{C}$; detector temperature $250^{\circ} \mathrm{C}$; and carrier gas, $\mathrm{N}_{2}$ at a flow rate of $1.00 \mathrm{ml} / \mathrm{min}$. The retention times and relative amount (\%) of the data components were obtained from GC peak areas.

\section{Data analysis}

In the case of evaluating the repellency of the test oil against mosquitoes, the average of bites in the treatment and control arms was used in calculating percentage protection. The percentage protection was calculated following the procedure $[34,35]$ :

$$
\% \text { protection }=\frac{(\mathrm{Nc}-\mathrm{Nt})}{(\mathrm{Nc})} \times 100 .
$$

Where Nc denotes the number of bites received by $(\mathrm{Nc})$ control arm and $\mathrm{Nt}$ stands for the number of bites received by treated arm.

Data from each set of three replicates obtained in the repellency tests were pooled to probit analysis for estimation of median effective dose $50 \%\left(\mathrm{ED}_{50}\right)$ values and their respective $95 \%$ Confidence Limits (95\%CL) using the PoloPlus 2.0 program [36]. Probit transformation of dose was analyzed. Results with $\mathrm{p}<0.05$ were considered to be statistically significant.

\section{Ethical considerations}

Six adult human volunteers including the research worker ( 3 male and 3 female) aged 30-45 years, were recruited from the students of Department of Microbial, Cellular and Molecular Biology, College of Natural Sciences, Addis Ababa University. Ahead of data collection, the objectives of the study and procedures were clearly explained and informed consent was obtained from each volunteer. The volunteers for the repellency test had good knowledge of malaria transmission, and 
Citation: Bekele D, Petros B (2017) Repellent Effects of Aloe pirottae (Aloaceae) Gel Extract and Brassica nigra (Brassicaceae) Essential Oil against the Malaria Vector, Anopheles arabiensis Patton (Diptera: Culicidae). Biochem Anal Biochem 6: 336. doi: 10.4172/2161-1009.1000336

Page 4 of 7

participants were assured that they could withdraw at any time without any consequences. This study was approved and ethical clearance was obtained from the Research Ethics Review Committee (RERC) of the College of Natural Sciences, Addis Ababa University (Reference number: RERC/002/05/2013).

\section{Results}

\section{Dermal irritation test}

The primary skin irritation scores are presented in Table 1. No erythema and edema was noted in any tested rabbits during the period of the exposure test with both products derived from $A$. pirottae and B. nigra.

\section{Repellence bioassay}

The results from the skin repellent activity of $A$. pirottae gel extract and $B$. nigra essential oil against A. arabiensis is given in Table 2.

Percentage repellency increased when their concentrations increased, whereas percentage repellency decreased when exposure time increased to 12 hours. The essential oil of $B$. nigra found to be more repellency than $80 \%$ methanol extract of $A$. pirottae. A higher concentration of $20 \%$ of $B$. nigra oil provided $91 \%$ repellency and $20 \%$ of $80 \%$ methanol extract of $A$. pirottae provided $52 \%$ repellency. The results clearly show that repellent activity was dose dependent. No repellent effect was observed in control (Figure 1).

Figure 1 shows the percentage protection for B. nigra essential oil, A. pirottae gel extract and DEET for A. arabiensis females for 3, 6, 9 and 12 hours' exposure. The repellent activity was very high at the initial

\begin{tabular}{|c|c|c|c|c|c|c|c|c|c|c|}
\hline \multirow{3}{*}{$\begin{array}{l}\text { Rabbit } \\
\text { No }\end{array}$} & \multirow{3}{*}{ Reactions } & \multicolumn{9}{|c|}{ Score of skin reaction } \\
\hline & & \multicolumn{3}{|c|}{ Control } & \multicolumn{3}{|c|}{$\begin{array}{c}\text { A. pirottae } \\
\text { extract }\end{array}$} & \multicolumn{3}{|c|}{ B. nigra oil } \\
\hline & & $3 \mathrm{~h}$ & $6 \mathrm{~h}$ & $9 \mathrm{~h}$ & $3 \mathrm{~h}$ & $6 \mathrm{~h}$ & $9 \mathrm{~h}$ & $3 \mathrm{~h}$ & $6 \mathrm{~h}$ & $9 \mathrm{~h}$ \\
\hline \multirow[t]{2}{*}{1} & Erythema & 0 & 0 & 0 & 0 & 0 & 0 & 0 & 0 & 0 \\
\hline & Edema & 0 & 0 & 0 & 0 & 0 & 0 & 0 & 0 & 0 \\
\hline \multirow[t]{2}{*}{2} & Erythema & 0 & 0 & 0 & 0 & 0 & 0 & 0 & 0 & 0 \\
\hline & Edema & 0 & 0 & 0 & 0 & 0 & 0 & 0 & 0 & 0 \\
\hline \multirow[t]{2}{*}{3} & Erythema & 0 & 0 & 0 & 0 & 0 & 0 & 0 & 0 & 0 \\
\hline & Edema & 0 & 0 & 0 & 0 & 0 & 0 & 0 & 0 & 0 \\
\hline \multirow[t]{2}{*}{4} & Erythema & 0 & 0 & 0 & 0 & 0 & 0 & 0 & 0 & 0 \\
\hline & Edema & 0 & 0 & 0 & 0 & 0 & 0 & 0 & 0 & 0 \\
\hline \multicolumn{2}{|c|}{ Primary Skin Irritation } & \multicolumn{3}{|c|}{ Nil } & \multicolumn{3}{|c|}{ Nil } & \multicolumn{3}{|c|}{ Nil } \\
\hline
\end{tabular}

Score for erythema: $0=$ No erythema, $1=$ Very slight erythema

Score for edema: $0=$ No edema, $1=$ Very slight edema

Table 1: Score of irritation and edema after application of gel containing extract of $A$. pirottae and essential oil of $B$. nigra with $20 \%$ concentration each in rabbits.

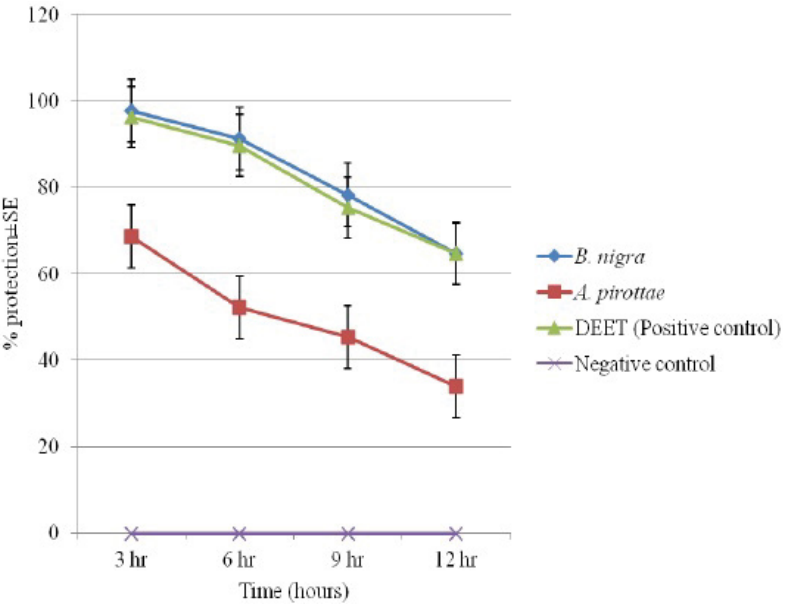

Figure 1: Percentage protection efficacy of $A$. pirottae gel extract and $B$. nigra essential oil with their controls against $A$. arabiensis tested at $20 \%$ concentration.

stage of exposure. Increase in the exposure period showed reduction in repellent activity.

The repellency data of $B$. nigra oil was more potent and/or comparable to DEET (Figure 1). However, the A. pirottae gel extract was less repellent than the others.

The repellent activity $B$. nigra oil was significantly higher $(\mathrm{p}<0.05)$ than that of $A$. pirottae gel extract (Figure 2). The results showed that repellent activity was dose dependent.

\section{Gas chromatography analysis of the components of $\boldsymbol{B}$. nigra oil}

Chemical components identification achieved by GC analysis revealed the presence of six peaks with varying amounts in products of B. nigra (Figure 3 and Table 3 ).

In peaks observed in the GC chromatogram of $B$. nigra oil, the first peak appeared at Retention time $\left(\mathrm{R}_{\mathrm{t}}\right)$ of 10.93 min with area $\%$ of 8.63 , $\mathrm{R}_{t}$ of second peak 15.16 min with $\%$ of $3.66, \mathrm{R}_{t}$ of third peak $26.65 \mathrm{~min}$ with \% of $8.58, \mathrm{R}_{t}$ of fourth peak 28.06 min with $\%$ of $72.55, \mathrm{R}_{t}$ of fifth peak 48.76 min with $\%$ of 3.18 , and $\mathrm{R}_{\mathrm{t}}$ of sixth peak 50.91 min with \% of 3.38 .

The retention time, area and the height of $B$. nigra oil was calculated from the GC peak and are summarized in Table 3. The main constituent of the oil of B. nigra in terms of relative percentage of total area in the chromatogram was $72.55 \%$ at retention time of $28.068 \mathrm{~min}$ (Figure 3 and Table 3).

\begin{tabular}{|c|c|c|c|c|c|c|c|c|}
\hline Treatment & Conc. (\%) & Number of adults & Observed repellency & Expected repellency & Residual & Profit value & Profit analysis & Chi-square \\
\hline \multirow{4}{*}{$\begin{array}{l}\text { A. pirottae } 80 \% \\
\text { methanol extract }\end{array}$} & 2.5 & 100 & 27 & 27.22 & -0.22 & 0.27 & \multirow{5}{*}{$\begin{array}{c}\text { ED50 }(95 \% \mathrm{CL}) \\
16.689(10.283- \\
52.194)\end{array}$} & \multirow{5}{*}{0.014} \\
\hline & 5 & 100 & 37 & 36.53 & 0.47 & 0.36 & & \\
\hline & 10 & 100 & 44 & 44.18 & -0.18 & 0.44 & & \\
\hline & 20 & 100 & 52 & 52.06 & -0.06 & 0.52 & & \\
\hline Control & 0 & 100 & 0 & 0 & 0 & 0 & & \\
\hline \multirow{4}{*}{$\begin{array}{l}\text { B. nigra essential } \\
\text { oil }\end{array}$} & 2.5 & 100 & 58 & 55.69 & 2.31 & 0.56 & \multirow{5}{*}{$\begin{array}{c}\text { ED50 }(95 \% \mathrm{CL}) \\
1.468(0.640- \\
2.277)\end{array}$} & \multirow{5}{*}{1.399} \\
\hline & 5 & 100 & 69 & 71.48 & -2.48 & 0.72 & & \\
\hline & 10 & 100 & 79 & 81.28 & -2.28 & 0.81 & & \\
\hline & 20 & 100 & 91 & 88.67 & 2.33 & 0.89 & & \\
\hline Control & 0 & 100 & 0 & 0 & 0 & 0 & & \\
\hline
\end{tabular}

Table 2: Median effective dosages (95\% Confidence Limits) and associated statistics for the repellents obtained with $80 \%$ methanolic gel extract of $A$. pirottae and essential oil of $B$. nigra at different concentrations against $A$. arabiensis mosquito after $6 \mathrm{~h}$. 
Citation: Bekele D, Petros B (2017) Repellent Effects of Aloe pirottae (Aloaceae) Gel Extract and Brassica nigra (Brassicaceae) Essential Oil against the Malaria Vector, Anopheles arabiensis Patton (Diptera: Culicidae). Biochem Anal Biochem 6: 336. doi: 10.4172/2161-1009.1000336

Page 5 of 7

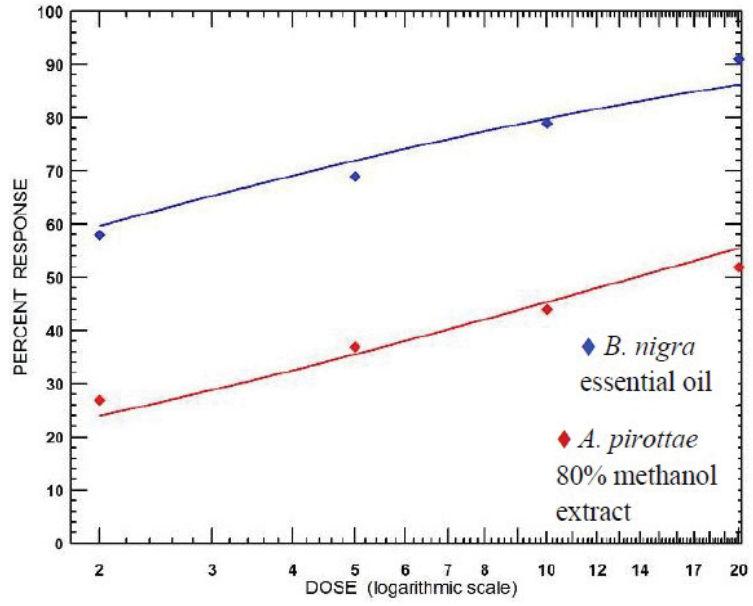

Figure 2: Percentage repellency of $A$. arabiensis after treatment with different concentrations of $80 \%$ methanol extract of $A$. pirottae gel and essential oil of $B$. nigra seed.

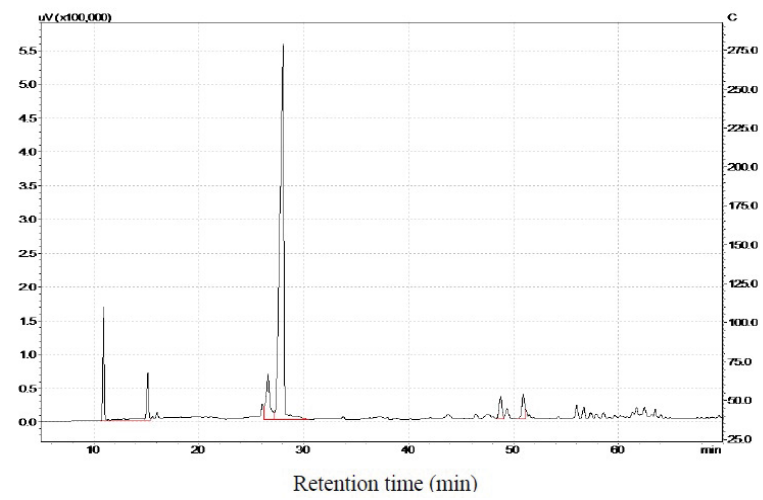

Figure 3: GC chromatogram of depicting profile of $B$. nigra essential oil.

\begin{tabular}{|c|c|c|c|c|c|}
\hline $\begin{array}{c}\text { Peak } \\
\text { No. }\end{array}$ & $\begin{array}{c}\text { Retention } \\
\text { time (min) }\end{array}$ & Peak area & Area (\%) & Peak height & Height\% \\
\hline 1 & 10.934 & 1733196 & 8.6354 & 167915.4 & 18.0082 \\
\hline 2 & 15.162 & 735420.8 & 3.6642 & 70450.5 & 7.5555 \\
\hline 3 & 26.652 & 1723176 & 8.5855 & 67595.7 & 7.2493 \\
\hline 4 & 28.068 & 14560640 & 72.5468 & 555856.9 & 59.6131 \\
\hline 5 & 48.769 & 638939.4 & 3.1834 & 33752.1 & 3.6198 \\
\hline 6 & 50.919 & 679340.4 & 3.3847 & 36870.2 & 3.9541 \\
\hline Total & & 20070713 & 100.0000 & 932440.8 & 100.0000 \\
\hline
\end{tabular}

Table 3: Gas chromatograhy peak table of $B$. nigra essential oil.

\section{Discussion}

Information that derives from tests for dermal irritation serves to identify the possible risk to the population who use and are exposed to substances such as mosquito repellents. In the present study, dermal application of $A$. pirottae gel extract and $B$. nigra oil produced no skin irritation in laboratory animals (rabbits) treated at $20 \%$ concentration. No signs of erythema and edema were observed. Lantana camara $\mathrm{L}$. flower extract in coconut oil provides $94.5 \%$ protection from Aedes albopictus (Skuse) and Ae. aegypti, with no undesirable adverse effects on human volunteers for 3 months after the application [37].

Our results showed that oils of $B$. nigra have significant repellent activity against $A$. arabiensis mosquito. However, the repellent effect was decreased as time increased which was in line with an earlier report by Govere et al. [38] who reported citronella (Cymbopogon excavates) oil gave $100 \%$ repellency for $2 \mathrm{~h}$, when it was evaluated in the laboratory against $A$. arabiensis and its repellency decreased to $59.3 \%$ after $4 \mathrm{~h}$. Another study conducted by Ansari et al. [39] showed that the peppermint (Mentha piperita) oil gave $94.1 \%$ protection for $6 \mathrm{~h}$, while mylol oil gave $95 \%$ protection for $7.2 \mathrm{~h}$. Govere et al. [40] also showed that the alcohol plant extract of Cymbopogon excavates and Pelargonium reniforme provided $66.7 \%$ and $63.3 \%$ protection against A. arabiensis for $3 \mathrm{~h}$, respectively. Some drops of neem (Azadirachta indica) oil vapourised from a mat at the door repel mosquitoes, keeping them off for approximately five to seven hours [41].

Plant-based repellents are still extensively used in this traditional way throughout rural communities in the tropics because for many of the poorest communities the only means of protection from mosquito bites that is available [10]. Utilizing homegrown repellents may reduce the need for foreign imports where exchange rate inequalities and transport costs inflate expenditure. Repellents as a method of preventing malaria are particularly promising in regions where vector mosquitoes bite early in the evening and in regions where vector mosquitoes have outdoor feeding habits, so that bed net use is unlikely to be very effective [9]. However, plant product repellents would have disadvantages, as they tend to last for a shorter period than synthetic preparations such as DEET (N,N-diethyl-meta-toluamide), therefore necessitating frequent reapplication.

Prabhu et al. [42] studied on the repellent activity of Moringa olifera against An. stephensi where he recorded the $90.41 \%$ repellency at $100 \%$ concentration and $23.28 \%$ repellency was recorded after the treatment of $20 \%$ concentration. According to Dube et al. [43], the repellent properties of the smoke and fresh volatile extracts were carried out and from Corymbia citriodora (52-76\%) and Ocimum suave (58-68\%) were found to be the most repellent, Ostostegia integrifolia (29-56\%) to be intermediate while Olea europaea (23-40\%) was the least repellent. Rajkumar and Jabanesan [44] investigated repellent effects of Solanum trilobatum against the Anopheles stephensi mosquito, and when they applied to the skin, the plant extract was found to have significant effects, which varied from 70-100 min, depending on the concentration of the extract. Tawatsin et al. [45] found that the steam distillate of turmeric plants (Curcuma longa) provided six hours protection against Anopheles dirus.

Most insect repellents in the market contain the chemical $\mathrm{N}$, $\mathrm{N}$-diethylmetatoluamide (DEET). It effectively blinds the insect's senses so that the biting or feeding instinct is not triggered by humans or animals [46]. Interestingly, B. nigra essential oil formulations were found to be more repellent against Anopheles mosquitoes than the approved synthetic repellent, DEET. These new findings may helpful for use as a mosquito repellent product to be applied in integrated malaria control strategies to gain maximum impact on vector control. Doseresponse studies of the oil of $B$. nigra indicate that it is more potent than DEET. The $80 \%$ methanol extract of $A$. pirottae is less potent than DEET.

Leaves of $B$. nigra are used to make a condiment and a spicy sauce used particularly during fasting seasons [28]. Brassica nigra found to be the potential repellent agents against the malaria vector suggest their potential uses as a broad spectrum. Furthermore, the broad spectrum of bioactivity of $B$. nigra oil is evident as reported by Indikar and Desale [47] with conceivable antibacterial activities. Jasim, [48] showed the activity of oils extracts of Brassica nigra seeds against pathogenic oral micro flora. 
Citation: Bekele D, Petros B (2017) Repellent Effects of Aloe pirottae (Aloaceae) Gel Extract and Brassica nigra (Brassicaceae) Essential Oil against the Malaria Vector, Anopheles arabiensis Patton (Diptera: Culicidae). Biochem Anal Biochem 6: 336. doi: 10.4172/2161-1009.1000336

Page 6 of 7

The repellent activity of $B$. nigra oil was comparable to previously screened plants using the Pine (Pinus longifolia) oil [49], who was reported to have strong repellent action against mosquitoes as it provided $100 \%$ protection against An. culicifacies and $97 \%$ protection against $C x$. quinquefasciatus for nine hours, respectively. The five most effective oils were those of Litsea (Litsea cubeba), Cajeput (Melaleuca leucadendron), Niaouli (Melaleuca quinquenervia), Violet (Viola odorata), and Catnip (Nepeta cataria), which induced a protection time of $8 \mathrm{~h}$ at the maximum and a 100\% repellency against Aedes, Anopheles, and Culex mosquitoes [50]. Nagpal et al. [51] reported that $A n$. culicifacies and $C x$. quinquefasciatus mosquitoes were unable to bite the protected person within $4 \mathrm{~h}$ after his her application of neem products, which were safe, and better than any other repellents without adverse reactions.

In this study, essential oil of $B$. nigra showed total six peaks with a major peak of $72.55 \%$ area with retention time $28.068 \mathrm{~min}$. The strong repellent activity of this oil could be attributed to this peak due to its higher percentage as revealed by GC peak area. However, other minor components like peak five and six may have little impact on repellent action. The repellency of the constituents of $B$. nigra oil was higher than DEET and therefore it is possible that the constituents from $B$. nigra oil could synergistically or independently cause repellent activities. Further work is needed to isolate, identify and exploit the lead bioactive constituent(s) as promising mosquito repellent.

Repllents of plant origin are sustainable alternatives to the synthetic chemicals and cost-effective [52] in which they do not pose hazards of toxicity to human and domestic animals and are easily biodegradable [53]. Furthermore, plants could be an alternative source for mosquito repellents because they constitute a potential source of bioactive chemicals and typically are free from harmful effects [54].

Unlike synthetic repellents, botanicals contain mixtures of various related compounds with different modes of action and hence the development of resistance to such products is somewhat difficult [55]. The mode of repellent action of $B$. nigra oil may block impulse transmission in mosquitoes nervous system. The mode of action of repellents is not actually to repel biting insects but seem to be to cancel out the attractant properties of the animal body or cancel the signals of attraction of animals [56].

In conclusion, the present findings showed that $B$. nigra essential oil and $A$. pirottae gel extract were not irritant when applied to rabbit skin and proved to be effective in repelling $A$. arabiensis. The plants could use by rubbing on the skin directly for mosquito repellents which assist in strengthening the control strategy in the fight against the disease malaria. Both $A$. pirottae and B. nigra are naturally abundant and can be grown and processed with low technology to produce affordable repellents for use against biting mosquitoes which are vectors of malaria.

\section{Recommendation}

The present study plants are easily available, accessible, and affordable; therefore the usage of traditional repellent plants should be promoted among the local residents in order to reduce man-vector contact and transmission of malaria. The superior repellency of $B$. nigra essential oil against $A$. arabienis under laboratory conditions must be studied further under field conditions with its formulated preparations for enhancing potency and stability of the extracts which are environmentally acceptable.

\section{Acknowledgements}

This study was financially supported by the Department of Microbial,
Cellular and Molecular Biology and Thematic Research of Malaria and other Parasitic Diseases, Addis Ababa University. The authors thank the individuals who served as subject volunteers. We also thank Dr. Asfaw Debella and Mr. Yehualashet Belete, the Centre for Traditional Medicine and Drug Research, Ethiopian Public Health Institute (EPHI) for their cooperation and allowed to use various instruments in their laboratory and for skilled technical assistance in processing of the plant materials and for running GC of the B. nigra oil; Mr. Fitsum Tesfaye (EPHI) for considerable help in rearing the mosquitoes and Prof. Ensermu Kelbessa (University of Addis Ababa) for plant identification.

\section{References}

1. WHO (2015) World Health Organization: Malaria Fact Sheet; No. 94.

2. Solomon H (2013) Ethiopia National malaria control program. In: Summary proceedings fourth annual malaria control program review in Ethiopia and Nigeria. Atlanta, Georgia.

3. Sachs J, Malaney P (2002) The economic and social burden of malaria. Nature 415: 680-685.

4. Breman J, Alilio M, Mills A (2004) Conquering the intolerable burden of malaria: what's new, what's needed: a summary. Am J Trop Med Hyg 71: 1-15.

5. Abose T, Yeebiyo Y, Olana D, Alamirew D, Beyene, Y, et al. (1998) Reorientation and definition of the role of malaria vector control in Ethiopia. WHO/MAL. 1085- 31

6. Abate A, Hadis M (2011) Susceptibility of Anopheles gambiae s.I. to DDT, malathion, permethrin and deltamethrin in Ethiopia. Trop Med Int Hlth 16: 486-491.

7. Yewhalaw D, Wassie F, Steurbaut W, Spanoghe P, Bortel WV, et al. (2011) Multiple insecticide resistance: an impediment to insecticide-based malaria vector control programme. Plos One 6: e16066.

8. Waka M, Hopkins RJ, Curtis C (2004) Ethnobotanical survey and testing of plants traditionally used against hematophagous insects in Eritrea. J Ethnopharmacol 95: 95-101.

9. Moore SJ, Lenglet AD (2004) An overview of plants used as insect repellents CRC Press. LLC.

10. Moore SJ, Lenglet A, Hill N (2006) Plant-Based Insect Repellents. In: Insect Repellents: Principles Methods, and Use. Boca Raton Florida: CRC Press.

11. Gupta RK, Rutledge LC (1994) Role of repellents in vector control and disease prevention. Am J Trop Med Hyg 50: 82-86.

12. Arnason JT, Philogene BJR, Morand $P$ (1989) Insecticides of plant origin. ACS Symp Ser 387. Am Chem Soc. Washington, DC.

13. Sukumar K, Perich MJ, Boobar LR (1991) Botanical derivative in mosquito control: a review. J Am Mosq Control Assoc 7: 210-237.

14. Seyoum A, Palsson K, Kunga S, Kabiru EW, Lwande W, et al. (2002) Traditional use of mosquito repellent plants in western Kenya and their evaluation in semifield experimental huts against Anopheles gambiae: ethnobotanical studies and application by thermal expulsion and direct burning. Trans R Soc Trop Med Hyg 96: 225-231.

15. Karunamoorthi K, Mulelam A, Wassie F (2008) Laboratory evaluation of traditional insect/mosquito repellent plants against Anopheles arabiensis, the predominant malaria vector in Ethiopia. Parasitol Res 103: 529-534.

16. Breman JG, Mills A, Snow RW (2006) Conquering malaria. In: Disease control priorities in developing countries (2ndedn), Washington: World Bank. 413-431.

17. Palsson K, Jaenson TGT (1999) Plant products used as mosquito repellents in Guinea Bissau, West Africa. Acta Tropica 72: 39-52.

18. Mittal PK, Subbarao SK (2003) Prospects of using herbal products in the control of mosquito vectors. Indian Council of Medical Research ICMR Bulletin 33: $1-10$.

19. Katz T, Miller J, Hebert A (2008) Insect repellents: historical perspectives and new developments. J Am Acad Dermatol 58: 865-871.

20. Trumble JT (2002) Caveat emptor: safety considerations for natural products used in arthropod control. Am Entomol 48: 7-13.

21. Novak RJ, Gerberg EJ (2005) Natural-based repellent products: efficacy for military and general public uses. J Am Mosq Contr Assoc 21: 7-11.

22. Schreck CE (1977) Techniques for the evaluation of insect repellents: a critica review. Ann Rev Entomol 22: 101-119. 
Citation: Bekele D, Petros B (2017) Repellent Effects of Aloe pirottae (Aloaceae) Gel Extract and Brassica nigra (Brassicaceae) Essential Oil against the Malaria Vector, Anopheles arabiensis Patton (Diptera: Culicidae). Biochem Anal Biochem 6: 336. doi: 10.4172/2161-1009.1000336

23. World Health Organization (2002) Traditional Medicine: Growing Needs and Potential. WHO Policy Perspectives on Medicines. World Health Organization, Geneva, pp: 1-6.

24. Belayneh A, Asfaw Z, Demissew S, Bussa NF (2012) Medicinal plants potential and use by pastoral and agro-pastoral communities in Erer Valley of Babile Wereda, Eastern Ethiopia. J Ethnobiol Ethnomed 8: 42

25. Bekele D, Asfaw Z, Petros B, Tekie H (2012) Ethnobotanical study of plants used for protection against insect bite and for the treatment of livestock health problems in rural areas of Akaki District, Eastern Shewa, Ethiopia. Topclass J Herbal Med 1: 40-52.

26. Bekele D, Petros B, Tekie H, Asfaw Z (2014) Larvicidal and adulticidal effects of extracts from some indigenous plants against the malaria vector, Anopheles arabiensis (Diptera: Culicidae) in Ethiopia. J Biofertil Biopestici 5:144.

27. Demissew S, Gilbert MG (1997)Aloaceae, in Sue Edwards, Sebsebe Demissew, Inga Hedberg (eds), Flora of Ethiopia and Eritrea, Volume 6, Hydrocharitaceae to Arecaceae (eds.), Addis Abab and Uppsala Pp: 117-333.

28. Jonsell B (2000) Brassicaceae, in Flora of Ethiopia and Eritrea, Volume 2 Part 1, Magnoliaceae to Flacourtiaceae (eds. Sue Edwards, Mesfin Tadesse, Sebsebe Demissew, Inga Hedberg), Addis Abab and Uppsala, pp: 121-154.

29. World Health Organization (1975) Manual on practical entomology in malaria part II, the WHO division of malaria and other parasitic diseases. World Health Organization. offset publication No.13. Geneva.

30. Garud A, Gautam A, Ganesan K, Kumar P, Prakash S, et al. (2011) Acute Toxicity Studies of Safer and More Effective Analogues of N,N-diethyl-2phenylacetamide. J Med Entomol 48: 1160-1166.

31. Draize JH, Woodard G, Calvery HO (1944) Methods for the study of irritation and toxicity of substances applied topically to the skin and mucous membranes. J Pharmacol Exp Ther 82: 377-390.

32. Shara M, Yasmin T, Kincaid AE, Limpach AL, Bartz J, et al. (2005) Safety and toxicological evaluation of a novel niacin-bound chromium (III) complex. J Inorg Biochem 99: 2161-2183.

33. World Health Organization (2009) Guidelines for efficacy testing of mosquito repellents for human skin. WHO/HTM/NTD/WHOPES/2009.4

34. Fradin MS, Day JF (2002) Comparative efficacy of insect repellents against mosquito bite. New Engl J Med 347: 13-18.

35. Venkatachalam MR, Jabanesan A (2001) Repellent activity of Ferronia elephantum Corr. (Rutaceae) leaf extract against Aedes aegypti (L.). Bioresour Technol 76: 287-288.

36. LeOra Software (2007) Polo-Plus, POLO for Windows, LeOra Software, 1007 B St. Petaluma. CA 94952. USA.

37. Dua VK, Gupta NC, Pandey AC, Sharma VP (1996) Repellency of Lantana camara (Verbenaceae) flowers against Aedes mosquitoes. J Am Mosq Control Assoc 12: 406-408.

38. Govere J, Durrheim DN, Du TN, Hunt RH, Coetzee M (2000) Local plants as repellents against Anopheles arabiensis, in Mpumalanga Province, South Africa. Cent Afr J Med 46: 213-216.

39. Ansari MA, Vasudevan P, Tandon M, Razdan RK (2000) Larvicidal and mosquito repellent action of peppermint (Mentha piperita) oil. Bioresour Technol 71: 267-271.
40. Govere J, Braack LEO, Durrheim DN, Hunt RH, Coetzee M (2001) Repellent effects on Anopheles arabiensis biting humans in Kruger Park, South Africa. Med Vet Entomol 15: 287-292.

41. Lüthi $P$, Bengelstorff $A$, Kamau $P$ (2008) Let us fight malaria: malaria special, pp: $1-4$.

42. Prabhu K, Murugan K, Nareshkumar A, Ramasubramanian N, Bragadeeswaran $S$ (2011) Larvicidal and repellent potential of Moringa oleifera against malarial vector, Anopheles stephensi Liston (Insecta: Diptera: Culicidae). Asian Pac J Trop Biomed 1: 124-129.

43. Dube FF, Tadesse K, Birgersson G, Seyoum E, Tekie H, et al. (2011) Fresh dried or smoked? Repellent properties of volatiles emitted from ethnomedicinal plant leaves against malaria and yellow fever vectors in Ethiopia. Malar J 10 375

44. Rajkumar S, Jabanesan A (2005) Oviposition deterrent and skin repellent activities of Solanum trilobatum leaf extract against the malaria vecto Anopheles stephensi. J Insect Sci 15: 1-3.

45. Tawatsin A, Wratten SD, Scott RR, Thavara U, Techadamrongsin Y (2001) Repellency of volatile oils from plants against three mosquito vectors. J Vector Ecol 26: 76-82

46. Rose RI (2001) Pesticides and public health: Integrated methods of mosquito management. Emerg Infect Dis 7: 17-23.

47. Indikar FR, Desale DJ (2009) Antimicrobial activity of oils of Brassica nigra and its formulation as an ointment. Inter J Pharma Rese develop 1: 1-5.

48. Jasim AS (2012) Antibacterial activity of oils extracts of Brassica nigra seeds on some bacteria isolated from plaque and healthy teeth in children (1-5) years. Basrah J Sci 30: 105-119.

49. Ansari MA, Mittal PK, Razdan RK, Sreehari U (2005) Larvicidal and mosquito repellent activities of Pine (Pinus longifolia, Family: Pinaceae) oil. J Vect Borne Dis 42: 95-99.

50. Amer A, Mehlhorn H (2006) Repellency effect of forty-one essential oils against Aedes, Anopheles, and Culex mosquitoes. Parasitol Res 99: 478-490.

51. Nagpal BN, Srivastava A, Vallecha N, Sharma VP (2001) Repellent action of neem cream against Anopheles culicifacies and Culex culicifacies. Curr Sci 80 1270-1271.

52. Ntonifor NN, Ngufor CA, Kimbi HK, Oben BO (2006) Traditional use of indigenous mosquito repellents to protect humans against mosquitoes and other insect bites in a rural community of Cameroon. East Afr Med J 85: 553558.

53. Das NG, Baruah I, Talukdar PK, Das SC (2003) Evaluation of botanicals as repellents against mosquitoes. J Vector Borne Dis 40: 49-53.

54. Isman MB (1995) Leads and prospects for the development of new botanical insecticides. Rev Pestic Toxicol 3: 1-20.

55. Mulla MS, Su T (1999) Activity and biological effects of neem products against arthropods of medical and veterinary importance. J Am Mosq Control Assoc 15: 133-152.

56. Davis EE (1985) Insect repellents: Concepts of their mode of action relative to potential sensory mechanisms in mosquitoes (Diptera: Culicidae). J Med Entomol 22: 237-243. 